\title{
Reconstruction and systemization of the methodologies for strategic environmental assessment in Taiwan
}

\author{
Ming-Lone Liou ${ }^{\mathrm{a}, *}$, Shin-Cheng Yeh ${ }^{\mathrm{b}, 1}$, Yue-Hwa Yu ${ }^{\mathrm{c}, 2}$ \\ ${ }^{a}$ Graduate Institute of Environmental Engineering, National Taiwan University, 9F-3, 100, Sec. 2, \\ Hoping E. Rd. Taipei 106, Taiwan, ROC \\ ${ }^{\mathrm{b}}$ Graduate Institute of Environmental Education, National Kaohsiung Normal University, 62, \\ Shenjung Rd., Yanchau Township, Kaohsiung 824, Taiwan, ROC \\ ${ }^{\mathrm{c}}$ Graduate Institute of Environmental Engineering, National Taiwan University, Room 302, \\ No. 71, Chou-Shan Rd., Taipei 106, Taiwan, ROC
}

Received 1 November 2004; received in revised form 1 August 2005; accepted 1 August 2005 Available online 23 September 2005

\begin{abstract}
This paper discusses the current SEA procedures and assessment methodologies, aiming to propose strategies that can lead to effective improvement in a newly industrialized Asian country, Taiwan. Institutional and practical problems with regard to the regulations and tools of SEA in Taiwan are compared to those in other countries. According to the research results, it is suggested that extra evaluation processes should be incorporated into the current assessment procedures to improve their scientific validity and integrity. Moreover, it is also suggested that the sustainability appraisal approaches be included in the SEA framework. In this phase, revised evaluation indicators associated with corresponding targets can be the first attempt for modifying the SEA system. It is believed that these can promote the operability in practice and also lead the whole assessment procedures to a direction closer to sustainable development. The trails that Taiwan has followed can help other countries that are going to adopt SEA to find a more effective and efficient way to follow.
\end{abstract}

(C) 2005 Elsevier Inc. All rights reserved.

Keywords: Strategic Environmental Assessment; SEA; Methodology; Matrix; Taiwan; Asia

\footnotetext{
* Corresponding author. Tel.: +88622733 4773; fax: +88622733 3293.

E-mail addresses: a4773@ms12.hinet.net (M.-L. Liou), scyeh@nknucc.nknu.edu.tw (S.-C. Yeh), yuehwayu@ccms.ntu.edu.tw (Y.-H. Yu).

${ }^{1}$ Tel.: +886 7605 1035; fax: +886 76051105 .

${ }^{2}$ Tel.: +88622363 6104; fax: +886223628043.
} 


\section{Introduction}

Strategic Environmental Assessment (SEA) is the systematic and comprehensive decisionaiding tool for deciding the government's strategic actions and corresponding alternatives. It was anticipated that through its implementation, environmental impacts of proposed policies, plans, and programs (PPPs) can be identified and emphasized in as-early stage in the decision-making process (Marsden, 2002; Partidário, 1999; Sadler and Verheem, 1996; Thérivel and Partidário, 1996; Thérivel et al., 1992). Although differences in the terms, forms, and assessment procedures for SEA implementations exist among nations, the core objective remains the same, i.e., to integrate environmental considerations into decision-making processes and to achieve sustainable development (Dalal-Clayton and Sadler, 2004; Fischer and Seaton, 2002; Partidário, 1996, 2002; Sadler, 1996; Verheem and Tonk, 2000).

Taiwan is a small island located in the west Pacific region with a population more than 23 million and an area of $36,000 \mathrm{~km}^{2}$. It is one of the most important economies in Asia, with a per capita GDP of US\$13,156 and an economic growth rate of $3.23 \%$ in 2003 . Taiwan has gained its economic growth at a price of environmental degradation since the 1960s. Water, air, and solid waste pollution problems were brought about by intensive industrialization and urban expansion without taking much environmental concerns into account. Thus, it is not surprising that as Taiwan's current competitiveness got an excellent rank of the 21 st according to the report of World Economic Forum (WEF et al., 2002), the environmental sustainability index score of Taiwan was ranked lower than the 100th in the international community in 2002 (Yeh et al., 2002).

Taiwan adopted the first official piece of legislation regarding SEA in 1994, which was earlier than most Asian countries (Briffett et al., 2003; Liou and Yu, 2004; Xiuzhen et al., 2002). However, as of the middle of 2004, Taiwan has only applied SEA to four cases, with more than half of the 11 designated plan/program categories required to conduct mandatory SEA still lack any assessment activities (EPA Taiwan, 2004). This disappointing result reflects the limited experience with incorporating environmental concerns and sustainability principles in Taiwan. The possible reasons for this relatively poor implementation may include resistance due to egoism of the administrative sector, rapid change of the unstable political climate, and unfamiliarity with SEA procedures and methodologies (EPA Taiwan, 2002; Liou et al., 2003).

Thus, this paper examined in detail the SEA procedures and assessment methodologies applied in Taiwan, with the hope that through literature reviews and comparative studies of international SEA systems, effective strategies aimed at practicality improvement and theory enhancement of SEA methodologies can be proposed, which can further enhance the promotion of SEA in Taiwan. It is also anticipated that the experiences of SEA implementations and the efforts to reconstruct/systemize the SEA methodologies in Taiwan can be referential to other countries with similar situations.

\section{Current situation and the dilemma for SEA implementation in Taiwan}

\subsection{Development history of SEA in Taiwan}

SEA first emerged in Taiwan as an official requirement in the government legislation as Article 26 of the 1994 Environmental Impact Assessment (EIA) Act. It was stated in Article 26 that "the procedures for environmental assessments of policies that may have potential significant adverse environmental impacts should be proposed by the competent authorities in the central government". At that time, as the concept of SEA was new to most legislators and the 
possibility of applying environmental assessments to intangible government policies had hardly been discussed, issues regarding SEA's regulatory design were placed in the legislative agenda directly without going through debates on its feasibility (Liou and Yu, 2004). Thus, in September 1997, the Environmental Protection Administration (EPA) of the Taiwan government promulgated the "SEA Guidelines for Government PPPs", in which the mandatory screening list and the contents required to be included in a SEA report were put in writing clearly for the first time.

The SEA framework of Taiwan has the basic logic and steps similar to those of the countries. However, there exist some specified characteristics and features. These are described in the following:

1. SEA procedures need to be initiated by the competent authorities:

According to the latest version of the SEA Guidelines for government PPPs ("Guidelines") published in December 2000, the environmental assessment report should be prepared by the competent authority for a designated PPP and be submitted to the Executive Yuan ${ }^{3}$ for review prior to the approval of such a PPP. The SEA procedure in accordance with the Guidelines is illustrated in Fig. 1.

2. PPPs required to conduct SEA are designated in a mandatory screening list:

The scope of SEA in Taiwan was defined by the mandatory screening list which mandated that SEA be applied to designated PPPs with potential adverse significant environmental impacts. The list includes 11 plans/programs in nine policy themes as listed in Table 1.

3. The items and rules of evaluation for SEA are defined in the SEA Manual:

The SEA Manual ("Manual") published in 1998 by the EPA established preliminary categories of evaluation, which is composed of eight components, including environmental carrying capacity, effect on natural ecosystems, public health and safety, utilization of natural resources, water resource systems and uses, cultural assets and harmony with natural landscape, international environmental treaties, and "others." Items for evaluation which corresponded to these components were then developed for use in the assessment procedure. The Manual also mandated that environmental impacts be assessed at the three levels of local, national and global aspects, and that strategies for mitigation and detailed interpretations should also be proposed.

4. Rankings are used to specify needs for description of mitigation strategies:

Each of the eight categories mentioned in the preceding section was given a descriptive guideline of ranking containing "significant positive impact (denoted by '++')", "positive impact (denoted by '+')", "neutral effect (denoted by ' $\bigcirc$ ')", "negative impact (denoted by '-')", and "significant negative impact (denoted by '- -')". A description of mitigation strategies with regard to components assessed as having "significant negative impacts" or "negative impacts" upon the environment must also be included. Moreover, according to the characteristics of the PPPs, opinion poll of the general public, economic effects, social acceptance, and other necessary environmental performances should also be complemented.

\subsection{Dilemma for SEA implementation}

It has been 10 years since the launch of SEA in accordance with Taiwan's EIA Act. However, until the middle of 2005, Taiwan has only applied SEA to the following four cases: National scheme for the location of industrial parks, Construction and management guidelines for golf

\footnotetext{
${ }^{3}$ The Executive Yuan is Taiwan's central governmental authority, often referred to as "The Cabinet" in many western countries.
} 


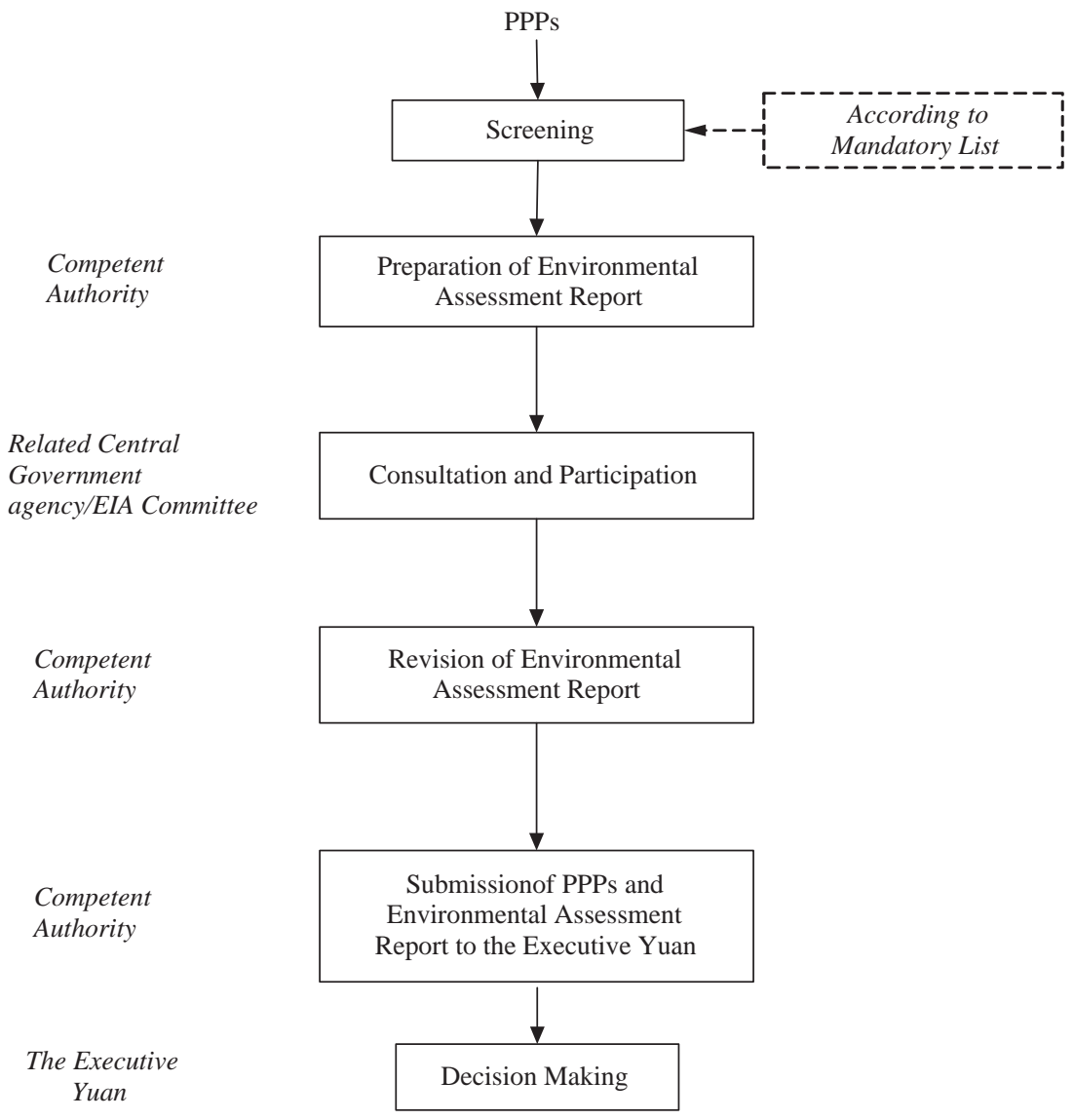

Fig. 1. Basic SEA procedure in Taiwan. Source: EPA Taiwan (2001).

courses, National water resources development plan, and Protected watersheds reduction plan. That is, more than half of the 11 plans/programs designated for mandatory SEA still lack any SEA implementation experience.

To understand and explore the reasons for this outcome, EPA Taiwan held several ad hoc meetings/workshops in 2002 and 2004, respectively, in which all the relevant competent authorities were invited to attend. Their talks were taped upon their agreement and transferred into written records. Keywords were searched both manually and with a computer software's aid. Thus, through examination of the opinions expressed and discussions among the workshop participants, the following challenges encountered during the SEA implementations can be generalized (EPA Taiwan, 2002, 2004):

1. unfamiliar with SEA procedures and methodologies;

2. difficulties with regard to conducting scoping process;

3. lack of accurate environmental baseline data for defining policy objectives/targets or estimating the total regulatory amount;

4. lack of well-defined quantification measures for evaluation criteria with respect to ranks, such as "++" or "- -", for use with the mandatory matrix method; 
Table 1

SEA mandatory screening list

\begin{tabular}{ll}
\hline Policy & Plan/program \\
\hline Energy & $\begin{array}{l}\text { Energy structure } \\
\text { Location of industrial parks } \\
\text { Industry }\end{array}$ \\
Land use & $\begin{array}{l}\text { Development of golf courses } \\
\text { Transformation of land for agricultural uses and } \\
\text { conservation for non-agricultural uses }\end{array}$ \\
& $\begin{array}{l}\text { Reducing the protected watersheds } \\
\text { Pig rearing }\end{array}$ \\
Mineral development & $\begin{array}{l}\text { Development and supply of sand/rock } \\
\text { Radioactive nuclear waste } \\
\text { management }\end{array}$ \\
Transportation & $\begin{array}{l}\text { Management re-treatment of the nuclear waste } \\
\text { generated by nuclear power plants }\end{array}$ \\
Waste management & Railroad and highway infrastructure \\
Water resources development & Household waste management \\
\hline
\end{tabular}

Source: EPA Taiwan (2001).

5. vagueness in implementation and monitoring in the SEA procedures;

6. lack of validness of the regulations regarding SEA;

7. the level of the current competent authority in the central government (i.e., EPA) is not high enough; and

8. slow implementation speed caused by an unstable political climate.

The eighth point listed above could be highly related to the rapid changes in Taiwan's political environment; whereas the other seven points reflected that the competent authorities were unfamiliar with SEA methodologies and that their administrative frameworks were incompatible with the SEA implementations. Thus, it was hoped that through reviews and studies of various international SEA systems, effective strategies aim at improving the practicality and effectiveness of SEA methodologies can be identified, which can be used to further enhance promotion and generalization of SEA in Taiwan.

\section{Overview of the international trends and practices of SEA}

\subsection{Issues of SEA procedures}

The issues of SEA procedure and assessment methodologies have been of key importance to the development and implementations of SEA in many countries. It can be observed that differences exist among various countries according to their political institutions and policymaking procedures (Partidário, 2002). It is also implied that applications of SEA should be associated closely with the framework and timing of decision-making in a country, so that the institutional function of SEA can ensure that the environmental impacts of the PPPs be assessed, and that assessments be carried out at an as-early stage and taken into consideration together with other economical and social factors (Glasson et al., 1999; Sadler and Verheem, 1996).

In general, a complete SEA procedure should contain the following steps (Arce and Gullon, 2000; Fischer, 2002; Sadler, 2001; Thérivel, 1996, 2004; Wood and Djeddour, 1992):

1. screening: determining whether a SEA is required;

2. defining the objectives/targets of the PPPs; 
3. scoping: analyzing the environmental situation and identifying the alternatives and impacts that should be assessed;

4. developing indicators for evaluation;

5. impact assessment and alternative analysis;

6. looking for consultation and suggestion from external sectors and experts;

7. public participation, for different sectors, at different stages;

8. submitting conclusion report of SEA;

9. proposing impact mitigation strategies;

10. connecting to the following SEA or EIA; and

11. monitoring and submitting environmental management plans.

Among these, the key steps include screening, scoping, impact assessment, and publishing conclusion report; on the other hand, public participation and alternative analysis can be implicitly embedded in various steps (Wood and Djeddour, 1992). This fundamental procedure has been applied to case studies in many countries, such as in the Netherlands (Netherlands Commission for EIA, 2002); European Union (European Union, 2001); South Africa (DEAT, 2000); and Canada (Environment Canada, 2000, 2003). Nonetheless, as can be seen in the above studies, though some basic common rules exist regarding the SEA procedure, details for SEA implementation should be designed based on the state/culture of each country. This is known as the "rules of flexibility" (Fischer, 2003; Verheem and Tonk, 2000).

\subsection{Techniques and methodologies of SEA}

The concept of SEA techniques and methodologies, unlike the diverse, precise, and highly operable tools used in environmental engineering or other science-based areas, is rather fuzzy. This perception originated from the fact that conducting environmental assessment with respect to conceptual legislative proposals or governmental policies is essentially a rather difficult task. Thus, Brown and Thérivel (2000), Partidário (2000) and Thérivel (1996) argued that there is not a generalized SEA methodology applicable to all PPPs. That is, there would be no "universal" or specified assessment techniques available, and that appropriate techniques and methodologies should be determined and applied in those steps in the SEA procedure on a case-by-case basis.

Moreover, in a straightforward sense, techniques and methodologies of SEA should be treated as a collection of tools in a "tool box", and that users should choose their own tools according to the needs of each unique case (Brown and Thérivel, 2000; Partidário, 2002). Due to the above considerations, SEA is becoming a newly blooming, interdisciplinary, and cross-sector field, in which integration and team work are emphasized.

Generally speaking, SEA techniques and methodologies were derived from those used for traditional EIA and policy appraisal/plan evaluation studies (Partidário, 2002; Sheate et al., 2001). As SEA practitioners consider that techniques and methodologies employed should be as simple as possible, checklist and matrix are two approaches often adopted because these are relatively straightforward, and thus, competent authorities and responding personnel cannot take difficulty in executing SEA as an excuse for avoiding conducting SEA. Thus, this can ensure that methodologies would not become the barrier for institutional promotion of SEA (UNEP, 2002). Nevertheless, applications employing relatively complicated analytical instruments, e.g., cost/benefit analysis (CBA) and multi-criteria analysis (MCA) did exist (Sadler, 1996). For example, CBA was employed in the Trans-Pennine Corridor (TPC) SEA in Northern England in 1997 (Dalkmann, 2001), also in Maastricht Aachen Airport (MAA) expansion SEA in southern 
Netherlands (Vreeker et al., 2002). In a SEA for the transportation policy of the 2004 Athens Olympic Games, both CBA and MCA were adopted as the central tools (Tsamboulas and Kopsacheili, 2003). A variety of possible techniques used for conducting the different steps of SEA were further analyzed and discussed in the literature including DHV (1994), Partidário (2002), Sadler (1996), Thérivel (2004) and UNEP (2002).

In addition, Marsden (2002) pointed out that, in terms of methodologies, SEA relies more on qualitative consideration and techniques than traditional EIA, and thus, expert judgment plays a more crucial role. The problem of selecting the appropriate assessment techniques and methodologies used in any specific case must be solved by referring to adequate implementation experiences accumulated through comparative studies of past schemes and applications.

The techniques used in the four SEA cases ever completed in Taiwan so far are summarized and integrated in Table 2. It can be observed that the matrix method was selected as the central tool of evaluation at this stage, as the implementation scheme was designed with the belief that assessment methodologies should not become the institutional barrier. However, it was still the case that the competent authorities did not initiate SEAs, even though it is regulated by the law, but tried not to touch environmental issues that could influence implementation of their projects. It is one of the reasons why there are only 4 out of the 11 PPPs in the mandatory list ever carried out so far. It was also anticipated that experiences should be accumulated through the practical applications, which would help Taiwan's SEA system to become well developed and deep rooted in this society. However, problems and implementation barriers were still observed under the current system, which would be discussed in the following section.

\section{Improvements of the current SEA methodologies in Taiwan}

\subsection{Integration of assessment processes into the current SEA procedure}

Based on the implementation experiences of other countries as listed in the preceding section, together with examination of Taiwan's SEA implementations conducted by Liou et al. (2003) and Liou and Yu (2004), the SEA system in Taiwan is judged to have developed to an acceptable level, even though the following problems have been identified as remained to be solved:

1. insufficient coverage of mandatory PPPs list for conducting SEA;

2. lack of requirements with regard to the scoping process; and

3. absence of policy monitoring and auditing.

In other words, the initiation mechanism of SEA and the administrative procedure has been smoothly operated in Taiwan regime, which has matched the development of SEA procedures in the international society.

Table 2

Methods/techniques applied to Taiwan's four SEA cases

\begin{tabular}{lllll}
\hline SEA cases & $\begin{array}{l}\text { National scheme } \\
\text { for the location } \\
\text { of industrial parks }\end{array}$ & $\begin{array}{l}\text { Construction and } \\
\text { management guidelines } \\
\text { for golf courses }\end{array}$ & $\begin{array}{l}\text { National water } \\
\text { resources } \\
\text { development plan }\end{array}$ & $\begin{array}{l}\text { Protected } \\
\text { watersheds } \\
\text { reduction plan }\end{array}$ \\
\hline Methods/techniques & Impact matrix & $\begin{array}{l}\text { GIS, Ad hoc approach, } \\
\text { Delphi method, AHP }\end{array}$ & Impact matrix & Impact matrix \\
\hline
\end{tabular}

Source: EPA Taiwan (2002) and Liou and Yu (2004). 
However, there exists a vital problem with the institutional design of Taiwan's SEA system, which is the lack of detailed guidelines. While steps in the SEA procedure were published (see Fig. 1), as well as simplified principal criteria for the assessment approaches and contents of assessment reports were described, the details regarding the conduct of impact identification and assessment, and the guidelines on preparation of SEA report have hardly been discussed. For a governmental official responsible for setting a SEA into action, she/he is probably familiar with administrative work but may not understand the assessment techniques and procedures and, hence, not feel confident of dealing with possible difficulties. Such a lack of detailed guidelines has been the major functional obstacle to promoting SEA in Taiwan.

In an attempt to mitigate this apparent obstacle and deficiency, the authors proposed a revised SEA procedure for use in Taiwan's SEA system based on the following revisions. First, the authors divided the current SEA process in Taiwan into two parts: the "administrative procedure" and the "assessment procedure." Second, the assessment procedure was incorporated into the administrative procedure without changing the basic framework of the latter. Thus, the basic SEA framework does not change, yet the assessment procedure is now embedded in the administrative procedure. According to the viewpoints of a person in charge of an SEA, this can make tasks need to do more organized, and thus, human resources allocation and schedule progress control can be easier to manage. Moreover, administrative and technical guideline can be produced separately and people involved in the SEA can easily find the guideline they need to follow. The revised integrated procedure is illustrated in Fig. 2.

In the revised procedure, all the steps originally belonging to the administrative procedure remain the same. However, to associate the scientific aspect of the assessment procedure with the administrative management principle of the administrative procedure, the assessment procedure was inserted after the step "prepare the draft of PPPs EA report" in the administrative procedure. The inserted assessment procedure follows the steps of "organize task team for conducting assessment", "scoping", "analysis, comparison, and evaluation of the proposal and alternatives," and "propose environmental impact mitigation strategies," to "documentation of the EA report". Tasks in each step were also provided in Fig. 2. It should be noted that the steps "scoping" and "documentation of the EA report" were both connected to the step "collect the comments/ opinions of the related authorities/organizations" in the administrative procedure, which was designed to place emphasis on public participation. Besides, following the step "announce and implement the PPPs" in the administrative procedure is a newly connected assessment procedure step "monitoring and evaluation", designed to match the spirit of continuous improvement in the project operational procedure aiming at sustainable development.

By comparing the proposed "Integrated Administrative and Assessment Procedure" (IAAP) and the existing SEA procedure in Taiwan with the elements and steps required in a complete SEA procedure as discussed in the preceding section, it can be seen that IAAP better meets the requirements for complete SEA procedure than existing practice in Taiwan.

\subsection{Enhancement in applying the matrix method for SEA in Taiwan}

The matrix method currently used in Taiwan's SEA process is based on the theory that the possible individual impacts on a specified environmental factor of an action or activity can be understood through the matrix of "potential environmental impact" vs. "environmental factor". It has the advantages of being simple to use, easy to understand, and capable of incorporating public opinions and perceptive impacts. However, there are no objectives or precise criteria defined by any competent authority for use in evaluating those impacts, and thus, it can be 


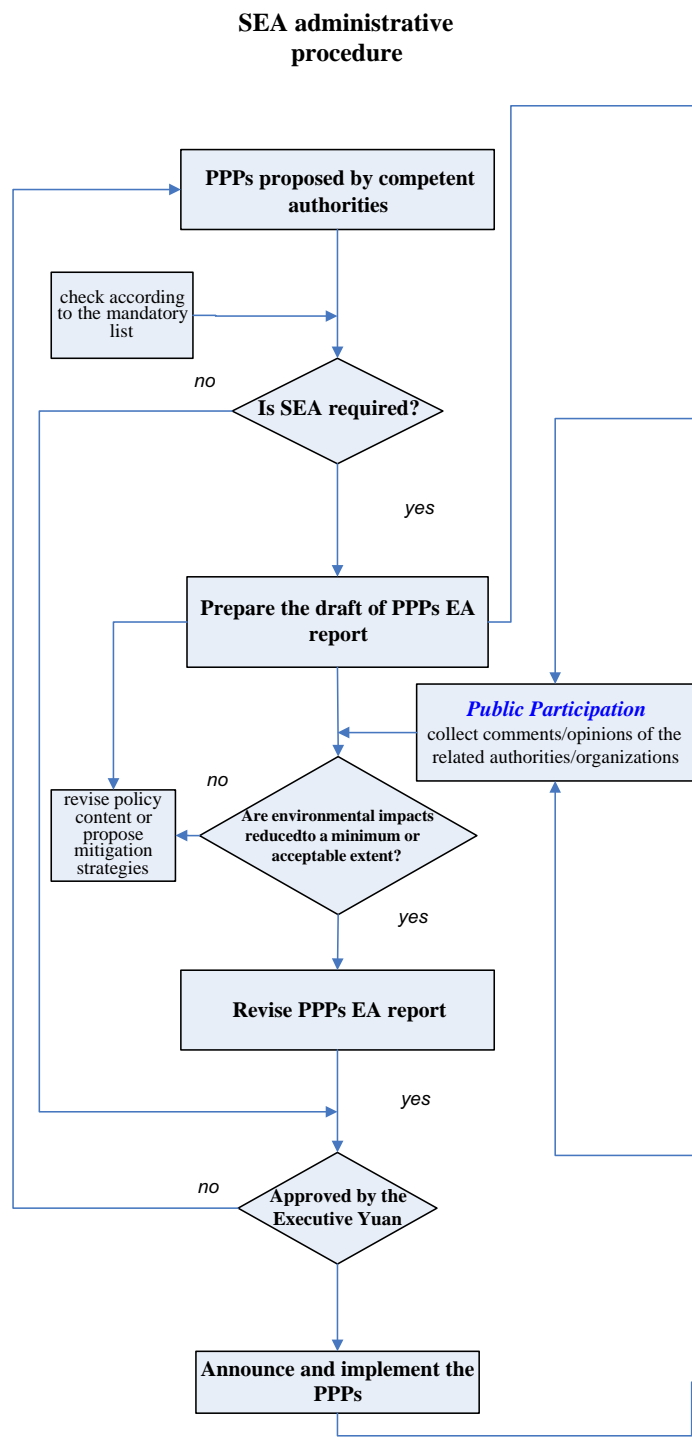

\section{SEA assessment procedure to be incorporated}

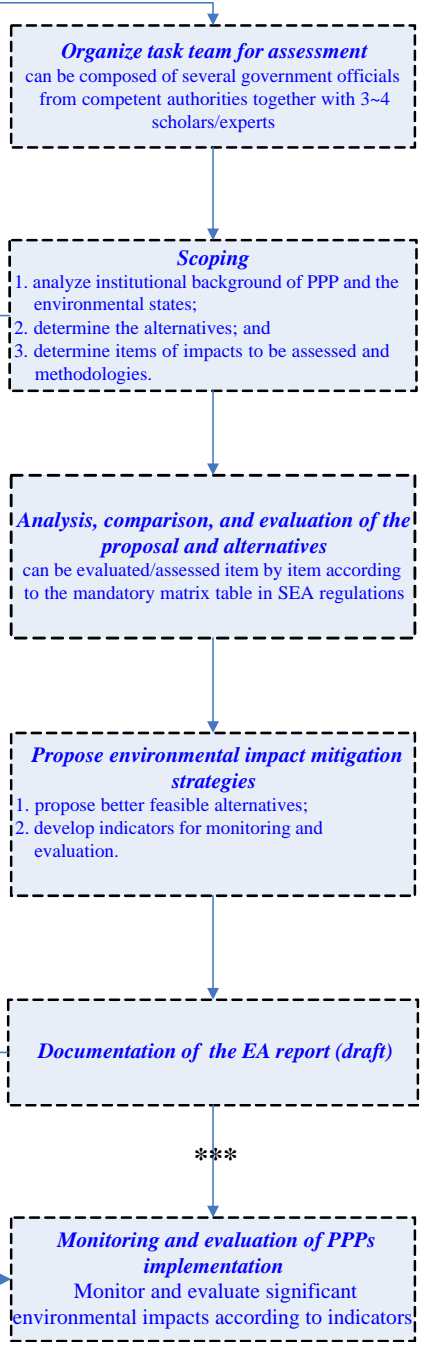

Fig. 2. Revised integrated procedure for Taiwan's SEA implementation.

concluded that the practices of SEA in Taiwan have been mostly based on "ad hoc" approaches. Though in some cases, results derived from scientific algorithms/models were used as reference, the SEA procedure as a whole is still far from being a "standard operating procedure" (SOP) or at least a "standard operating framework" (SOF).

As there are no quantifiable indicators and corresponding targets or criteria for use in the evaluation associated with the current matrix method, in practice, further development of some implicit or explicit indicators in line with those items or environmental factors under evaluation would be needed. Moreover, targets and criteria would often be determined by any means just to make the evaluation tasks possible, and this could make the whole evaluation process rather uncertain and subjective. In fact, different evaluation ratings and SEA conclusion tend to arise 
with the change in the competent authorities or committee members. This is also one of the issues of most concern to the competent authorities in Taiwan (EPA Taiwan, 2002).

Furthermore, in the current impact matrix method, e.g., the Air Quality Cell in the Matrix Table defined for SEA (Table 3) for the environmental carrying capacity category, even though the table name implied indicators, only air quality-relevant pollutant categories were listed, not the actual indicators; also lacking was the instructions and targets in evaluating the impacts from a sustainable development perspective.

To incorporate operability and sustainable development considerations into the current impact matrix, the contents of the current matrix need to be further enhanced. An example of incorporating the sustainability assessment (SA) concept and framework into the impact matrix used in Taiwan is demonstrated in Table 4. As indicated by Koernoev (2002), Partidário and Moura (2000) and Thérivel (2004), the operability of sustainability assessment can only be achieved through coupling of indicators with targets; the authors thus adopted the credible and widely used sustainability indicators in Taiwan while maintaining the same matrix categories when constructing the matrix shown in Table 4. For the indicator part, the Taiwan Sustainable Development Indicators (TSDI) published by the Council for Economic Planning and Development (CEPD, 2003) and indicators system established by Liou et al. (2003) were used; while air pollutant target values for 2006 and 2011 adopted in the National Environmental Protection Plan (NEPP) and Taiwan Agenda 21 were used as targets. Detailed explanations were also provided as notes in the table when deemed necessary.

Using approaches similar to the above in creating Table 4, all the matrix tables used in the current SEA impact matrix method can be converted to include sustainability considerations. However, an attempt at such conversions is an enormous task which would require considering numerous differences in various indicators and targets and would need to employ the ad hoc approach to reach consensus in order for the results to be representative.

As for the criteria and mechanism that can be used for evaluation of the fulfillment extent of sustainability for indicators listed in the matrix, the rules suggested by Partidário and Moura (2000) can be employed. That is, assuming the target value of an indicator is $Y$, while the actual value measured or observed is $X$, the following rules can apply:

1. if $X<Y^{\prime}$, the actual value is lower than target value, the condition is acceptable and that sustainability is maintained;

2. if $X=Y^{\prime}$, the current condition is at a critical state, and some action is required in order to maintain the trend/state of sustainability;

3. if $X>Y^{\prime}$, the actual value is greater than the target value, the condition is unacceptable and that sustainability is breached.

Table 3

SEA matrix: air quality indicator

\begin{tabular}{lllll}
\hline Indicators and variables & Local & National & Global & Mitigation strategies \\
\cline { 2 - 3 } & Evaluation & & \\
\hline
\end{tabular}

Air Quality

-Suspended particulates (TSP and $\mathrm{PM}_{10}$ )

-Sulfur dioxide $\left(\mathrm{SO}_{2}\right)$

-Nitrogen dioxide $\left(\mathrm{NO}_{2}\right)$

-Ozone $\left(\mathrm{O}_{3}\right)$

- Lead $(\mathrm{Pb})$

Source: EPA Taiwan (2001). 
Table 4

Proposed impact matrix enhanced by indicators and targets

\begin{tabular}{|c|c|c|c|c|c|c|}
\hline \multirow{3}{*}{$\begin{array}{l}\text { Items and content of } \\
\text { PPPs to be assessed }\end{array}$} & \multirow{3}{*}{$\begin{array}{l}\text { Corresponding } \\
\text { indicators in the } \\
\text { "Sustainable Taiwan" } \\
\text { indicator system }\end{array}$} & \multicolumn{4}{|l|}{ Evaluation target } & \multirow{3}{*}{$\begin{array}{l}\text { Commentary/ } \\
\text { mitigation } \\
\text { strategies }\end{array}$} \\
\hline & & \multicolumn{2}{|l|}{ NEPP } & \multicolumn{2}{|l|}{ Agenda 21} & \\
\hline & & Target for 2006 & Target for 2011 & Target for 2006 & Target for 2011 & \\
\hline \multicolumn{7}{|c|}{ Environmental carrying capacity } \\
\hline 1. Air quality & $\begin{array}{l}\text { - Annual average } \\
\text { of TSP }\left(\mathrm{PM}_{10}\right) \\
\left(\mu \mathrm{g} / \mathrm{m}^{3}\right)\end{array}$ & $\begin{array}{l}\text { Percent of days in a } \\
\text { year with PSI larger } \\
\text { than } 100<2\end{array}$ & $\begin{array}{l}\text { Percent of days } \\
\text { in a year with PSI } \\
\text { larger than } 100<1.5\end{array}$ & $\begin{array}{l}\text { Percent of days } \\
\text { in a year with PSI } \\
\text { larger than } 100<2\end{array}$ & $\begin{array}{l}\text { Percent of days } \\
\text { in a year with PSI } \\
\text { larger than } 100<1.5\end{array}$ & \\
\hline $\begin{array}{l}\square \text { Suspended } \\
\text { particulates } \\
\left(\mathrm{TSP}, \mathrm{PM}_{10}\right)\end{array}$ & $\begin{array}{l}\text { Percent of days } \\
\text { in a year with } \\
\text { PSI }>100\end{array}$ & - $\mathrm{CO}(\mathrm{ppm})<0.689$ & - $\mathrm{CO}(\mathrm{ppm})<0.689$ & & $\begin{array}{l}\text { - } \mathrm{SO}_{X} \text { reduced by } \\
470,000 \text { tons }\end{array}$ & \\
\hline $\begin{array}{l}\square \text { Sulfur dioxide } \\
\left(\mathrm{SO}_{2}\right)\end{array}$ & - $\mathrm{CO}_{2}$ emission & - $\mathrm{O}_{3}(\mathrm{ppm})<0.047$ & - $\mathrm{O}_{3}(\mathrm{ppm})<0.047$ & & $\begin{array}{l}\text { - } \mathrm{NO}_{X} \text { reduced by } \\
725,000 \text { tons }\end{array}$ & \\
\hline $\begin{array}{l}\square \text { Nitrogen } \\
\text { dioxide }\left(\mathrm{NO}_{2}\right)\end{array}$ & & - $\mathrm{NO}_{2}(\mathrm{ppm})<0.020$ & - $\mathrm{NO}_{2}(\mathrm{ppm})<0.020$ & & $\begin{array}{l}\text { Accumulative } \\
\text { reduction rate of } \mathrm{SO}_{X} \\
\text { and } \mathrm{NO}_{X}>60 \%\end{array}$ & \\
\hline $\begin{array}{l}\square \text { Ozone }\left(\mathrm{O}_{3}\right) \\
\square \text { Lead }(\mathrm{Pb})\end{array}$ & & $\begin{array}{l}\text { - } \mathrm{SO}_{2}(\mathrm{ppm})<0.006 \\
\mathrm{PM}_{10}\left(\mu \mathrm{g} / \mathrm{m}^{3}\right)<55.15 \\
\text { Pb }\left(\mu \mathrm{g} / \mathrm{m}^{3}\right)<0.06 \\
\text { TSP reduced by at } \\
\text { least } 560,000 \\
\text { metric tons and with a } \\
\text { reduction rate }>40 \%\end{array}$ & $\begin{array}{l}\text { - } \mathrm{SO}_{2}(\mathrm{ppm})<0.006 \\
\mathrm{PM}_{10}\left(\mu \mathrm{g} / \mathrm{m}^{3}\right)<55.15 \\
\mathrm{~Pb}\left(\mu \mathrm{g} / \mathrm{m}^{3}\right)<0.05 \\
\text { TSP reduced by at } \\
\text { least } 710,000 \\
\text { metric tons and with a } \\
\text { reduction rate }>50 \%\end{array}$ & $\begin{array}{l}\text { On protection of } \\
\text { the ozone layer: } \\
\text { eliminate HCFCs } \\
\text { production by } 2030\end{array}$ & & \\
\hline
\end{tabular}

Source: integrated from EPA (2002) and Liou et al. (2003). 
In the practice of SEA applications, quantification of the extent of sustainability could be needed. In this case, the concept of membership functions for fuzzy sets theory can be employed (Zadeh, 1965; Zimmermann, 1991), in which the function value can indicate the extent of sustainability changing with the actual value of a specified variable of concern. Fig. 3 illustrates a potential membership function in which the extent of sustainability decreases from 1.0 at $X=Y$ to 0.0 when $X$ is equal to an upper bound tolerance limit $T_{\mathrm{U}}$. The overall performance or score of a "component" or "aspect" is composed of a number of indicators which can then be obtained through using pre-defined operators such as maximum-minimum or weighted summation of respective membership function values or extents of sustainability.

In the third case above, corrective actions need to be proposed in order to improve or correct the current state of unsustainable condition, so as to push the extent of sustainability upward 1.0. For this case, the sustainable development indicators listed in NEPP or Taiwan Agenda 21 (see Table 4) have been breached and that either acceptable corrective actions need to be proposed or that the development planning need to be revoked.

\section{Conclusion and recommendations}

In this paper, the current situation and major challenge of Taiwan's SEA system is reviewed and discussed, with the methodologies and assessment procedures for conducting SEA emphasized. In terms of initiation, timing and development of SEA system, Taiwan's progress is comparable to the developed countries' and in line with international trend; however, Taiwan lags behind on the actual implementation because of some institutional and practical constraints and would require more government efforts in order to promote its implementation. This paper proposed to improve the existing tools used in the current SEA system instead of advocating the system change, as the authors believe that the growth of SEA is part of the evolution of the society in general, and that unless the current system has been thoroughly reviewed and implemented, a leap-frog type of conversion is unlikely to occur. As proposed in this paper, the IAAP, the improved assessment techniques and methodologies, and the enhanced impact matrix, can all be used as assessment tools by the competent authorities in Taiwan. Table 5 summarizes those problems, suggestions, and the reasons why these suggestions were made in this paper for a clear review.

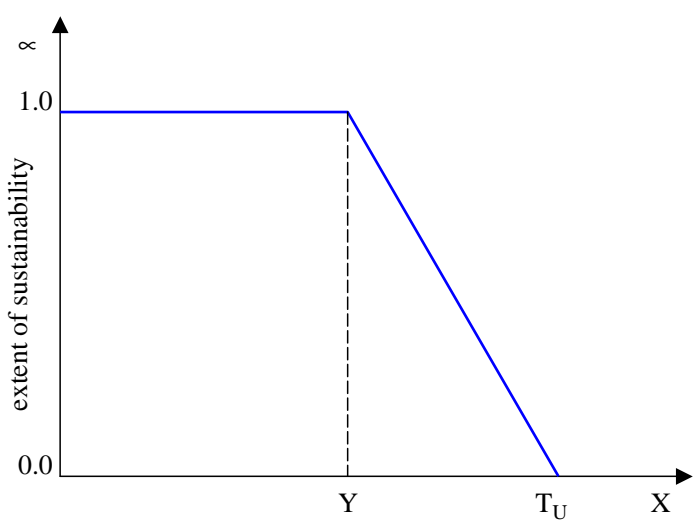

Fig. 3. Fuzzy membership function to measure the extent of sustainability. 
Table 5

The major problems, suggestions, and the corresponding reasons with regard to Taiwan's SEA system mentioned in this paper

\begin{tabular}{|c|c|c|}
\hline Problem & Suggestions & Reasons \\
\hline $\begin{array}{l}\text { The component authorities are } \\
\text { not familiar with SEA procedures } \\
\text { and methodologies }\end{array}$ & $\begin{array}{l}\text { - To improve the existing } \\
\text { tools currently used instead } \\
\text { of changing them }\end{array}$ & $\begin{array}{l}\text { - Growth of SEA is a gradual } \\
\text { revolutionary process } \\
\text { - The current system needs to } \\
\text { be implemented first }\end{array}$ \\
\hline $\begin{array}{l}\text { - Lack of clear guidelines to follow } \\
\text { when conducting SEA }\end{array}$ & $\begin{array}{l}\text { - Divide the current SEA process } \\
\text { into the administrative and the } \\
\text { assessment procedure } \\
\text { - The assessment procedure was } \\
\text { incorporated into the administrative } \\
\text { procedure without changing the } \\
\text { basic framework }\end{array}$ & $\begin{array}{l}\text { - Guidelines can be produced } \\
\text { separately and management } \\
\text { of SEA projects can be } \\
\text { relatively easier }\end{array}$ \\
\hline $\begin{array}{l}\text { - Categories instead of real indicators } \\
\text { are offered in the matrix table }\end{array}$ & - Coupling indicators with targets & $\begin{array}{l}\text { - Indicators proposed and used } \\
\text { by the government are relatively } \\
\text { less controversial as SEAs needs } \\
\text { to be executed by the government }\end{array}$ \\
\hline $\begin{array}{l}\text { No objectives or precise criteria } \\
\text { defined for use in evaluating impacts } \\
\text { of indicators in the matrix table }\end{array}$ & $\begin{array}{l}\text { - Adopting officially used sustainable } \\
\text { development indicators in Taiwan to } \\
\text { be used in SEA's matrix tables } \\
\text { - Use the target values announced } \\
\text { by the government in National } \\
\text { Environmental Protection Plan or } \\
\text { other official documents }\end{array}$ & $\begin{array}{l}\text { - Targets for corresponding } \\
\text { indicators can be picked up easily }\end{array}$ \\
\hline
\end{tabular}

The basic concept and objective of the current international SEA practice is to incorporate the consideration of sustainability into SEA. The current SEA system in Taiwan does consider impacts which cover the essential aspects of traditional EIA. However, from the viewpoint of SEA, the fundamental dimensions of sustainability in the environmental, economic, social, and institutional aspects were not incorporated into the framework systematically. To promote the integrity and completeness of the SEA system in Taiwan, classification of potential impacts, as well as the evaluation framework, which includes hierarchy of indicators, need to be modified. Thus, the redesigned matrix tables proposed in this paper should allow SEA to be conducted in a manner more consistent with the goals of national sustainable development in Taiwan. However, the task of incorporating sustainability assessment into result interpretation in future SEA process, in order to develop the next generation SEA in Taiwan, is certain to be a daunting task and would require great devotion and efforts of all SEA practitioners in Taiwan.

For countries working on the legislation and application of SEA, two important lessons of interest may be learned from the experiences of SEA implementations in Taiwan. Firstly, although the same basic SEA principles apply to different countries, local implementation of SEA needs to be fit into the actual political systems in accordance with the unique socioeconomic and cultural characteristics of each country. Secondly, the status of development of a country is also an important consideration in devising individual SEA scheme. The SEA implementation can be successful only with the SEA legislation in place which is backed by systematic and useable SEA procedures designed based on comprehensive and practical methodologies. This situation tends to exist when a country is highly developed in environmental, social and economic aspects. The SEA development approach which Taiwan has adopted may help other countries that are going to adopt SEA in finding a more effective and efficient approach to introduce SEA, which hopefully can contribute to bringing the Earth closer to the status of sustainable development. 


\section{References}

Arce R, Gullon N. The application of Strategic Environmental Assessment to sustainability assessment of infrastructure development. Environ Impact Asses Rev 2000;20:393-402.

Briffett C, Obbard JP, Mackee J. Towards SEA for the developing nations of Asia. Environ Impact Asses Rev 2003;23:171-96.

Brown AL, Thérivel R. Principles to guide the development of strategic environmental assessment. Impact Assess Proj Apprais 2000;18:183-9.

Council for Economic Planning and Development (CEPD) Taiwan. Sustainable development indicators for Taiwan. Taipei, Taiwan; 2003.

Dalal-Clayton B, Sadler B. Strategic environmental assessment: an international review with a special focus on developing countries and countries in transition, final draft. London: IIED; 2004.

Dalkmann H. Strategic Environmental Assessment (SEA): a comprehensive approach for transport planning. Paper prepared for the CCICED transport working group seminar on integrated transport planning, Beijing, PR China, April 21-22, 2001; 2001.

Department of Environmental Affairs and Tourism (DEAT). Strategic environmental assessment in South Africa. South Africa: Guideline Document; 2000.

DHV Environment and Infrastructure BV. Existing strategic environmental assessment methodology. Compiled for the European Commission DGXI, Brussels; 1994.

Environment Canada. Strategic environmental assessment at Environment Canada: how to conduct environmental assessments of policy, plan and program proposals, Quebec, Canada; 2000.

Environment Canada. Strategic environmental assessment at Environment Canada: an integrated approach to the environmental assessment of policy, plan and program proposals, Quebec, Canada; 2003.

Environmental Protection Administration (EPA) Taiwan Homepage, 2001. http://www.epa.gov.tw (accessed 2004).

Environmental Protection Administration (EPA) Taiwan. The Establishment of the methodologies of SEA in Taiwan, Taipei, Taiwan; 2002.

Environmental Protection Administration (EPA) Taiwan. The study on the system reform of SEA in Taiwan, midterm report, Taipei, Taiwan; 2004.

European Union. Directive 2001/42/EC of the European Parliament and of the Council of 27 June 2001 on the assessment of the effects of certain plans and programmes on the environment. Off J Eur Commun 2001;197:30-7.

Fischer B. Policy, plan, programme environmental assessment in England, the Netherlands, and Germany: practice and prospects. Environ Plann B Plann Des 2002;29:159-72.

Fischer B. Strategic environmental assessment in post-modern times. Environ Impact Asses Rev 2003;23:155-70.

Fischer B, Seaton K. Strategic environmental assessment: effective planning instrument or lost concept? Plan Pract Res 2002; 17:31-44.

Glasson J, Therivel R, Chadwick A. Introduction to environmental impact assessment 2nd ed. London: Spon Press; 1999.

Koernoev L. Strategic environmental assessment and the decision-making process. In: Devuyst D, editor. How green is the city? New York: Columbia University Press; 2002. p. 157-73.

Liou ML, Yu YH. The development and implementation of strategic environmental assessment in Taiwan. Environ Impact Asses Rev 2004;24:337-50.

Liou ML, Kuo NW, Yu YH. Sustainable indicators for strategic environmental assessment in Taiwan. Paper presented at the Fourth International Conference on Ecosystems and Sustainable Development, Siena, Italy; 2003.

Marsden S. Strategic environmental assessment: an international overview. In: Marsden S, Dovers S, editors. Strategic environmental assessment in Australasia. NSW: The Federation Press; 2002. p. 1-23.

Netherlands Commission for EIA. Environmental Impact Assessment in the Netherlands, Views from the Commission for EIA in 2002, The Netherlands; 2002.

Partidário MR. Strategic environmental assessment: key issues emerging from recent practice. Environ Impact Asses Rev 1996; $16: 31-55$.

Partidário MR. Strategic environmental assessment-principles and potential. In: Petts J, editor. Handbook of environmental impact assessment). London: Blackwell; 1999. p. 60-73.

Partidário MR. Elements of an SEA framework-improving the added-value of SEA. Environ Impact Asses Rev 2000;20:647-63.

Partidário MR. Course manual of strategic environmental assessment. The Hague, The Netherlands: IAIA; 2002.

Partidário MR, Moura F. Strategic sustainability appraisal - one way of using SEA in the move toward sustainability. In: Partidário MR, Clark R, editors. Perspectives on strategic environmental assessment. USA: CRC Press; 2000. p. $29-43$. 
Sadler B. Environmental assessment in a changing world: evaluating practice to improve performance. International study of the effectiveness of environmental assessment. Australia: Australian EIA Network; 1996. p. $139-64$.

Sadler B. A framework approach to strategic environmental assessment: aims, principles and elements of good practice. Proceedings of International Workshop on Public Participation and Health Aspects in Strategic Environmental Assessment, Szentendre, Hungary; 2001. p. 11-24.

Sadler B, Verheem R. Strategic environmental assessment: status, challenges and future directions, report no 53 . Ministry of Housing, Spatial Planning and the Environment, The Hague, The Netherlands; 1996.

Sheate W, Richardson J, Aschemann R, Palerm J, Stehen U. SEA and intergration of the environment into strategic decision-making, vol. 1. Main Report to the European Commission, London; 2001.

Thérivel R. SEA methodology in practice. In: Thérivel R, Partidário MR, editors. The practice of strategic environmental assessment. London: Earthscan Publications; 1996. p. 30-44.

Thérivel R. Strategic environmental assessment in action. London: Earthscan Publications; 2004.

Thérivel R, Partidário MR. Introduction. In: Thérivel R, Partidário MR, editors. The practice of strategic environmental assessment. London: Earthscan Publications; 1996. p. 3-14.

Thérivel R, Wilson E, Thompson S, Heaney D, Pritchard D. Strategic environmental assessment. London: Earthscan Publications; 1992.

Tsamboulas D, Kopsacheili AG. Methodological framework for strategic assessment of transportation policies: application for Athens 2004 Olympic Games. Transp Res Rec 2003;1848:19-28.

United Nations Environment Program. UNEP'S environmental impact assessment training resource manual. 2nd ed. Geneva, Switzerland: UNEP/ETB Briefs on Economics, Trade and Sustainable Development; 2002.

Verheem R, Tonk J. Enhancing effectiveness: strategic environmental assessment: one concept, multiple forms. Impact Assess Proj Apprais 2000;18:177-82.

Vreeker R, Nijkamp P, Welle CT. A multicriteria decision support methodology for evaluating airport expansion plans. Transp Res Part D 2002;7:27-47.

Wood C, Djeddour M. Strategic Environmental Assessment: EA of policies, plans and programmes. Impact Assess Bull 1992;10:3-22.

World Economic Forum, Yale Center for Environmental Law and Policy, Center for International Earth Science Information Network of Columbia University, 2002. 2001 Environmental Sustainability Index, http://www.ciesin. columbia.edu/indicators/ESI/.

Xiuzhen C, Jincheng S, Jinhu W. Strategic environmental assessment and its development in China. Environ Impact Assess Rev 2002;22:101-9.

Yeh SC, Yu YH, Kuo YH. Where are we in the World Village? computation of the ESI score for Taiwan. Urban Planning (Taiwan) 2002;20:445-79.

Zadeh LA. Fuzzy sets. Inf Control 1965;3:338-53.

Zimmermann HJ. Fuzzy sets theory and its applications. 2nd ed. Boston, USA: Kluwer Academic Publishers; 1991.

Ming-Lone Liou is a PhD of the Graduate Institute of Environmental Engineering of National Taiwan University. He has participated in research to improve the methodologies of SEA in Taiwan for years. His ongoing research efforts are aimed at the development of a comprehensive SEA system and promoting environmental sustainability in Taiwan.

Shin-Cheng Yeh is an associate professor and is also the chairman of the Graduate Institute of Environmental Education at National Kaohsiung Normal University in Taiwan. He has participated in many research projects in the field of water resources management, environmental systems analysis, environmental education, and strategic environmental assessment.

Yue-Hwa Yu is a Professor at the Graduate Institute of Environmental Engineering of National Taiwan University. His research interests focus on the development of Environmental Impact Assessment and Strategic Environmental Assessment in Taiwan. 